\title{
Design of Laboratory Test Equipment for Automotive Oil Filters to Evaluate the Technical Life of Engine Oil
}

\author{
Hujo L’ubomír ${ }^{1}$, Jablonický Juraj ${ }^{1}$, Markovič Jaromír ${ }^{2}$, Tulík Juraj ${ }^{1}$ *®D , Simikić Mirko ${ }^{3}$, \\ Zastempowski Marcin ${ }^{4}$ (D) and Janoušková Romana ${ }^{1}$ \\ 1 Department of Transport and Handling, Faculty of Engineering, Slovak University of Agriculture in Nitra, \\ Tr. A. Hlinku 2, 94901 Nitra, Slovakia; lubomir.hujo@uniag.sk (H.L'.); juraj.jablonicky@uniag.sk (J.J.); \\ xjanouskova@is.uniag.sk (J.R.) \\ 2 The Slovak Legal Metrology (SLM), Hviezdoslavova 1124/31, 97401 Banská Bystrica, Slovakia; \\ markovic@slm.sk \\ 3 Faculty of Agriculture in Novi Sad, University of Novi Sad, 21000 Novi Sad, Serbia; simikic@polj.uns.ac.rs \\ 4 Faculty of Mechanical Engineering, UTP University of Science and Technology, Al. prof. S. Kaliskiego 7, \\ 85-796 Bydgoszcz, Poland; zastemp@utp.edu.pl \\ * Correspondence: juraj.tulik@uniag.sk; Tel.: +421-37-641-4531
}

Citation: L'ubomír, H.; Juraj, J.; Jaromír, M.; Juraj, T.; Mirko, S.; Marcin, Z.; Romana, J. Design of Laboratory Test Equipment for Automotive Oil Filters to Evaluate the Technical Life of Engine Oil. Appl. Sci. 2021, 11, 483. https://doi.org/ 10.3390/app11020483

Received: 5 November 2020 Accepted: 2 January 2021 Published: 6 January 2021

Publisher's Note: MDPI stays neutral with regard to jurisdictional clai$\mathrm{ms}$ in published maps and institutional affiliations.

Copyright: (C) 2021 by the authors. Licensee MDPI, Basel, Switzerland. This article is an open access article distributed under the terms and conditions of the Creative Commons Attribution (CC BY) license (https:// creativecommons.org/licenses/by/ $4.0 /)$.

\begin{abstract}
The main aim of the article is to present the design of laboratory test equipment, which is appropriate for monitoring the efficiency of oil filters and the system for evaluating the technical life of engine oils in terms of possible extension of service intervals. The functionality of the designed laboratory test equipment for the filtration of motor oils was verified by a practical experiment with a verification measurement and assessment of the suitability of the hydraulic circuit elements and the designed sensing equipment. The laboratory equipment enables the testing of oil filters with different filtration capacity during simultaneous testing in two separate hydraulic circuits with differently contaminated engine oil, while it enables laboratory measurements to be performed while simulating operating conditions.
\end{abstract}

Keywords: laboratory test equipment; filter; hydraulic circuit; sensors

\section{Introduction}

The lubrication system is an integral part of the reciprocating internal combustion engine, which we consider to be the most used power unit. The main signification of lubrication lies in its beneficial effect on the passive resistances of moving engine parts, ensuring the functionality of important engine nodes and keeping the parameters within the required limits during its life.

The lifetime and stability of lubricating oils depends on the operating conditions, especially on the operating temperature of the oil, the technological process of lubrication, the design of the lubrication system and the working environment. Normal operating oil temperature is in the range of $50{ }^{\circ} \mathrm{C}$ to $70^{\circ} \mathrm{C}$. Each increase of the operating temperature by $10{ }^{\circ} \mathrm{C}$ shortens the life of the oil lubricant in the lubrication system by $1 / 3$ to $1 / 2$, which is a big disadvantage. The solution to the problem, in the event of higher operating temperatures, is to modify the lubrication system, e.g., by using a cooler, changing the size of the oil tank, adjusting the circulation number, or other design modifications [1].

Changes in the physical and chemical properties of engine oil that occur during its use during engine operation cause carbon, paint, sludge, water contamination, dirt, unburned fuel residues and other products that are trapped in the oil filters [2].

Motor oils are the most demanding lubricants in terms of the choice of base oils and suitable additives. Their functional properties result from the requirements for perfect engine lubrication, keeping the internal parts of the engine clean and neutralizing acidic products from combustion. According to Kučera [3], oil pollution is the most common and 
serious source of machine failure. The oil itself is extremely thermally loaded and stressed during operation. The oil fill temperature can be up to $150{ }^{\circ} \mathrm{C}$, the temperature on the connecting rod bearings up to $180^{\circ} \mathrm{C}$ and the temperature on the first piston ring up to $250{ }^{\circ} \mathrm{C}$ and more.

When designing the laboratory equipment for the evaluation of engine oil filtration, we relied on the technical characteristics of oil filters and hydraulic pumps, the hydraulic elements used in the test hydraulic circuit, the characteristics of the internal combustion engine, and the calculations performed.

We require hydrostatic converters to run quietly, smoothly and with reliability [4]. Tóth [5] deals with the issue of lubricating tribological systems, which are formed by a functional pair operating under different conditions of combined friction.

The determination of the extent of engine oil contamination before use in the test circuit of the designed laboratory equipment is performed by evaluating the physical-chemical properties of the used oil (engine oil taken). The equipment also allows monitoring the life of oil filters, with variously contaminated engine oil, with the possibility of extending engine oil change service intervals depending on changes in the physical-chemical properties of engine oil and filter efficiency. Semjonovs [6] focuses on increasing the engine oil change interval in his work. These laboratory tests can be performed in parallel in two hydraulic circuits, which can significantly reduce the testing time of the filter capabilities of oil filters, without the risk of engine damage, provided that the tests were performed under operating conditions. Diagnosis of the oil or oil conditions indicates oil contamination and contaminants, warns of possible faults and allows faults to be prevented [7]. In the case of use with short running times, the engine oils, regardless of category, must be changed after two years at the latest [8].

\section{Material and Methods}

Oil aging catalysts contain impurities, such as water in the oil, which increases corrosivity, forms an emulsion and impairs lubricity properties [2].

Analysis of lubricating oils during engine operation can be used to determine and detect the following:

- $\quad$ probability of failure of lubrication of functional parts;

- $\quad$ suitability of the type of oil;

- level of oil wear;

- determination of the oil change interval;

- $\quad$ evaluation of the technical condition of functional parts [8].

The measurement of the associated quantities in the hydraulic system is performed by means of combined sensors. They allow simultaneous measurement of pressure, temperature, and volumetric flow rate in different types of tests. For some purposes, especially diagnostic and lifetime tests, it is useful to monitor the hydraulic power, which is obtained by multiplying the volumetric flow rate $Q$ and pressure $p$ [9]. Figures 1 and 2 show the digital record unit HYDAC 3100 with sensors, German devices that enable flow rate measurement in the range of 6 to $60 \mathrm{dm}^{3} / \mathrm{min}, 15$ to $300 \mathrm{dm}^{3} / \mathrm{min}$, and 40 to $600 \mathrm{dm}^{3} / \mathrm{min}$ at a pressure up to $40 \mathrm{MPa}$ and a temperature up to $100{ }^{\circ} \mathrm{C}$. It is possible to connect a flow sensor and a pressure sensor (Figure 2) in the body of the device, while the associated sensing device can be built directly into the tube. All sensors can be connected to the HMG 3010 hand-held digital measuring device using connecting cables (Figure 1). 


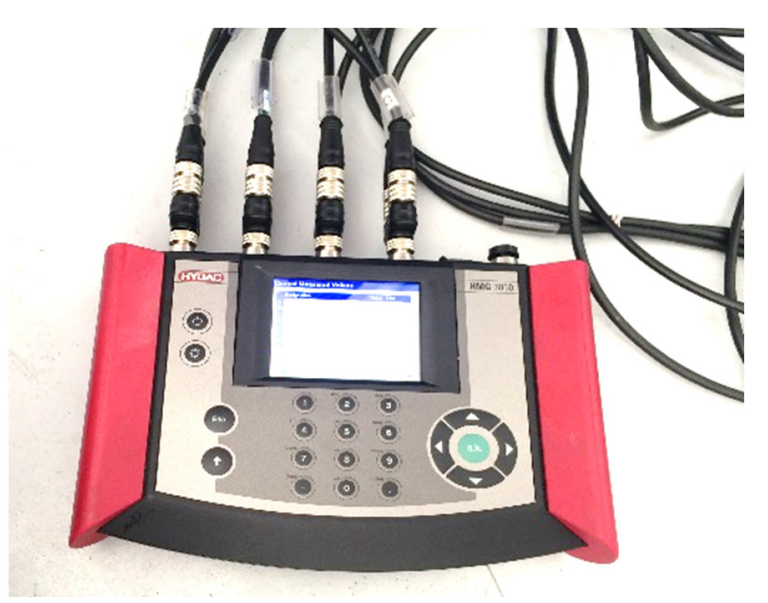

Figure 1. HMG 3110.

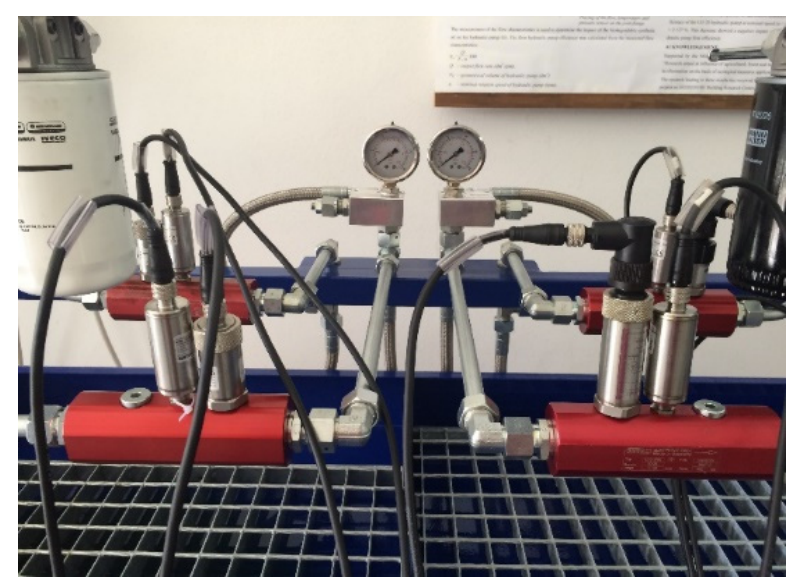

Figure 2. Flow and pressure sensors for an HMG 3010 measuring device.

Measurement of quantities in the hydraulic circuit of the laboratory test equipment can be divided into main and secondary measured quantities. To measure the required quantities, measuring devices will be used to set and check the parameters and diagnose faults in the hydraulic circuit.

We distinguish two basic groups of measuring instruments:

1. measuring instruments displaying the instantaneous value of the measured quantity (volumetric flow rate meter, pressure gauge, and thermometer);

2. measuring instruments for recording the measured value, the course of the measured value being displayed on a time axis.

\subsection{Main Measured Quantities of Hydraulic Mechanisms}

Theoretical low rate-realization of oil flow in front of and behind oil filters in the circuit of the laboratory test equipment is performed continuously by a speed flow meter. The flow meters were connected to the hydraulic circuit for flow rate checking. The flow rate of the proposed laboratory device is regulated by the flow rate of the hydraulic pump, this rpm having been determined with the rpm range of the internal combustion engine.

- The amount of fluid flowed per unit time, i.e., steady-state volume or mass over time:

$$
Q_{T}=V_{T H} \cdot n_{T H}
$$

or

where: 
$Q_{T H}$-theoretical flow rate of hydraulic pump, $\mathrm{m}^{3} / \mathrm{s}$

$V_{T H}$-theoretical volume of hydraulic pump, $\mathrm{m}^{3}$

$n_{T H}$-theoretical hydraulic pump rotation speed, $\mathrm{rpm}$

Pressure-the measurement is performed on the mechanical and electrical principle, in this case when measuring the oil pressure at the inlet and outlet of the oil filter we use pressure gauges on the electrical principle. The principle of changing the electrical resistance due to a change shape in the area of elastic deformations is used to sense the pressure by means of a strain gauge sensor.

When measuring pressure, we use basic definitions:

- $\quad$ force $F(\mathrm{~N})$ acting perpendicular to the unit area $S\left(\mathrm{~m}^{2}\right)$ :

$$
p=\frac{F}{S}=\frac{m \cdot g}{S}
$$

- hydrostatic pressure is important for the pressure drop in the filter and the main formula consists of a column of pressure fluid with height $h$ and density $p$ :

$$
p=\rho \cdot g \cdot h
$$

where:

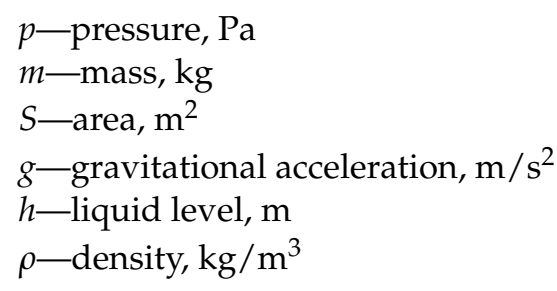

\subsection{Secondary Measured Quantities of Hydraulic Mechanisms}

Temperature-monitoring the oil temperature is important due to the change in viscosity depending on the oil temperature. We measured it through the temperature sensor in the tube Hydac ETS 4144-A000 and another sensor in the tank (Table 1).

Viscosity - measurement of kinematic viscosity and calculation of dynamic viscosity is specified by standard EN ISO 3104, procedure for the determination of transparent and opaque liquid petroleum products, lubricants, and related products. The method consists in measuring the flow time of a given volume of the test liquid, caused by gravity, with a calibrated glass capillary viscometer under known test conditions. Capillary viscometers for the determination of kinematic viscosity are of different shapes and for each range of viscosities it is necessary to use a viscometer with a suitable constant [10].

Volumetric flow rate, pressure, and temperature sensors will be used in both circuits to evaluate the filtration of a given oil. Flow sensors will monitor the values in the measuring circuit, while monitoring changes depending on the clogging of oil filters by contaminants. The pressure change will be continuously monitored throughout the circuit using four strain gauge pressure sensors. The temperature of the working fluid will be monitored in the tank, or directly in the circuit, to ensure the operating temperature corresponding to the temperature of the engine oil in operation.

The flow rate characteristics of the oil filters are measured using sensors located in front of and behind the filters, together with the measurement of the pressure change. The required working temperature of the engine oil is achieved by heating the oil with an electric heater in the tank. Derivation of pressure or resistance in the hydraulic circuit of the laboratory test equipment is performed by means of a throttle valve with the stabilization of a pressure drop. 
Table 1. Basic data of volumetric flow rate, pressure, and temperature sensor [11].

\begin{tabular}{|c|c|c|}
\hline \multicolumn{3}{|c|}{ Flow rate sensor Hydac EVS 31 04-A-0060-000 } \\
\hline Parameter & Unit & Value \\
\hline Power supply & V DC & $10-32$ \\
\hline Signal & $\mathrm{mA}$ & $4-20$ \\
\hline Fluid temperature & ${ }^{\circ} \mathrm{C}$ & $-20 \div 90$ \\
\hline Ambient temperature & ${ }^{\circ} \mathrm{C}$ & $-20 \div 70$ \\
\hline Measured flow rate & $\mathrm{dm}^{3} / \mathrm{min}$ & $6 \div 60$ \\
\hline Working pressure maximum & $\mathrm{MPa}$ & 40 \\
\hline Accuracy of measurement & $\%$ & $\leq 2$ \\
\hline \multicolumn{3}{|c|}{ Pressure sensor Hydac HDA 4744-A-250-000 } \\
\hline Power supply & V DC & $12-30$ \\
\hline Supply current maximum & $\mathrm{mA}$ & 100 \\
\hline Measured maximum pressure & $\mathrm{MPa}$ & 25 \\
\hline Accuracy of measurement & $\%$ & $\leq \pm 0.25$ \\
\hline Safety type according to DIN 40050 & IP & 65 \\
\hline \multicolumn{3}{|c|}{ Temperature sensor Hydac ETS 4144-A000 } \\
\hline Thermal range & ${ }^{\circ} \mathrm{C}$ & $-25 \div 100$ \\
\hline Operating current & $\mathrm{mA}$ & $4 \div 20$ \\
\hline Operating voltage & $\mathrm{V}$ & $8 \div 32$ \\
\hline Protection class & IP & 65 \\
\hline Response time & $1 / \mathrm{s}$ & 4 \\
\hline Accuracy of measurement & $\%$ & $\leq \pm 0.8$ \\
\hline \multicolumn{3}{|c|}{ Temperature sensor in tank ZPA EKOREG KSTz.eEX Pt100/B/3w } \\
\hline Measuring range & ${ }^{\circ} \mathrm{C}$ & $-30 \div 170$ \\
\hline Classification & - & II 3 G EX nA II (T3)-T6 \\
\hline Accuracy of measurement & $\%$ & \pm 1 \\
\hline Degree of coverage & IP & 65 \\
\hline Maximum overpressure at temperature & $\mathrm{MPa} /{ }^{\circ} \mathrm{C}$ & $4 / 100 ; 3.1 / 180$ \\
\hline
\end{tabular}

\section{Results}

The laboratory equipment for the evaluation of engine oil filtration was designed to assess the properties of various engine oil filters and their filtration capabilities. Tests on this equipment will shorten the testing time of oil filters, as they are not tied to the operating conditions of the intercity bus, but we will induce the operating conditions by simulation. Tests of suitability for the use of different types of oil filters will be evaluated on the basis of the influence of contaminated working fluids on the change of pressure in the hydraulic circuit and the change of flow rate in the hydraulic circuit of the test equipment. At the same time, we will monitor and evaluate changes in the physical-chemical properties of the assessed motor oils. In the proposed laboratory test equipment, hydraulic elements are used in the reference and test hydraulic circuit: tandem gear hydraulic pump, safety pressure valve, throttle valve with stabilization, three-way valve, filter, heater, tank and measuring devices.

Hydraulic scheme Figure 3 of the proposed test laboratory equipment of engine oil filters consists of three hydraulic circuits, where circuit A can be called a reference measuring circuit, circuit $B$ a test circuit, and circuit $C$ a control circuit of measuring devices. The drive of the device is provided by an electric motor connected to a frequency converter to achieve the required rpm of the gear hydraulic pump, the rpm is sensed by a rpm sensor. Subsequently, a tandem hydraulic pump with specific properties (e.g., the ability to withstand high temperatures) is connected in the device, through which we pump oil through the filter device in the hydraulic circuit A and B. The tank includes coarse filters that separate coarse dirt. The hydraulic circuits are secured against overload by pressure valves, in the function of relief valves. The formation of resistance in the hydraulic circuit is realized by means of throttle valves with the stabilization of pressure drop. Temperature 
and pressure sensors are located behind the throttle valves. There are two oil filters in the primary and secondary circuits, while filter (1) is the filter recommended by the vehicle manufacturer and filter (2) constitutes an alternative use. The direction of the oil to the individual filters is ensured by changing the position on the three-way valve. Circuits $\mathrm{A}$ and $B$ consist of a tank in which a heater is included, which we use to reach the operating temperature. Behind the heater is a thermometer and a manometer. Subsequently, the circuit branches off and by means of a three-way valve, the flow is directed to the filters (1) or, if necessary, to filters (2). A three-way valve is re-introduced from the filters at the outlet tube. Behind the three-way valve is a combination of the sensors for digital recording unit Hydac HMG 3110, which is used to sense operating conditions in the hydraulic circuit, temperature, pressure, and flow sensor.

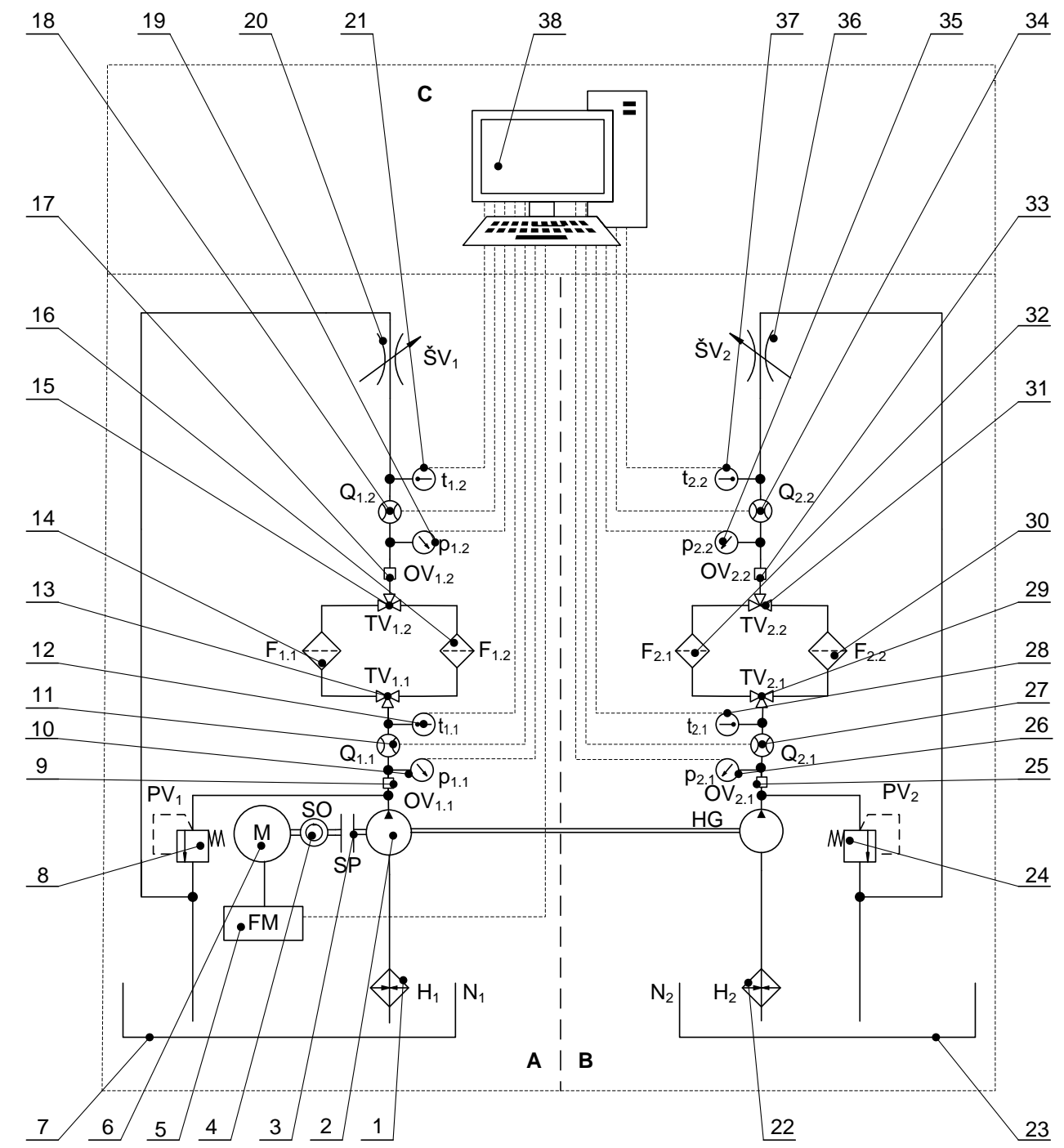

Figure 3. Equipment for comparing the flow properties of oil filter materials in the lubrication circuits of internal combustion engines. Legend: A—reference measuring circuit; B-test measuring circuit; C—recording and evaluation circuit; 1, 22heaters; 2-tandem hydraulic pump; 3-coupler; 4-rpm sensor; 5-frequency converter; 6-electric motor, 7, 23-tanks; 8, 24-safety valves; 10, 19, 26, 35-pressure sensors; 11, 18, 27, 34-flow sensors; 12, 21, 28, 37-temperature sensors; 13, 15, 29, 31-three-way valves; 14, 32-original filter materials; 16, 30—testes filter materials; 9, 17, 25, 33-sampling points; 20, 36-throttle valves; 38 - computer with software; $\mathrm{HG}$-tandem hydraulic pump; $\mathrm{H}_{1}, \mathrm{H}_{2}$ - heaters; $\mathrm{N}_{1}, \mathrm{~N}_{2}$ - tanks; FMfrequency converter; $\mathrm{SP}$ — coupler; $\mathrm{SO}$-speed sensor; $\mathrm{PV}_{1}, \mathrm{PV}_{2}$ — safety valves; $\mathrm{Q}_{1.1}, \mathrm{Q}_{1.2}, \mathrm{Q}_{2.1}, \mathrm{Q}_{2.2}$-flow sensors; $\mathrm{p}_{1.1}$, $\mathrm{p}_{1.2}, \mathrm{p}_{2.1}, \mathrm{p}_{2.2}$ - pressure sensors; $\mathrm{t}_{1.1}, \mathrm{t}_{1.2}, \mathrm{t}_{2.1}, \mathrm{t}_{2.2}$-temperature sensors; $\mathrm{F}_{1.1}, \mathrm{~F}_{1.2}, \mathrm{~F}_{2.1}, \mathrm{~F}_{2.2}$-filters in circuit $\mathrm{A}$ and $\mathrm{B}$; $\mathrm{TV}_{1.1}$, $\mathrm{TV}_{1.2}, \mathrm{TV}_{2.1}, \mathrm{TV}_{2.2}$-three-way valves; $\mathrm{OV}_{1.1}, \mathrm{OV}_{1.2}, \mathrm{OV}_{2.1}, \mathrm{OV}_{2.2}$-sampling point; $\mathrm{M}$-electric motor; $\mathrm{SV}_{1}, \check{S} \mathrm{~V}_{2}$ 一throttle valves. 
The reference measuring circuit A consists of an electric motor 6 connected to a frequency converter 5 for setting and maintaining the required speed of the first Section 2 of the tandem hydraulic pump in the range from the minimum to the maximum. The first Section 2 of the tandem hydraulic pump is connected to the electric motor 6 via a first coupler 3. An rpm sensor 4 is arranged between the electric motor 6 and the first Section 2 of the tandem hydraulic pump and a first safety valve 8 is connected to the output of the first Section 2 of the tandem hydraulic pump. In the lower part of the reference measuring circuit A, a first fluid tank 7 is located, which is connected to the first heater 1 and to the first Section 2 of the tandem hydraulic pump for sucking the working fluid into the first three-way valve 13. Between the first Section 2 of the tandem hydraulic pump and the first pressure sensor, a first sampling outlet 9 is located. A first pressure sensor 10, a flow sensor 11 and a temperature sensor 12 are arranged between the first heater 1 and the first three-way valve 13, the first three-way valve 13 being connected to the first original filter 14 and to the first tested filter 16. The first original filter 14 and the first tested filter 16 are connected at the outlet to the second three-way valve 15. A second sampling outlet 17 is located between the second three-way valve 15 and the second pressure sensor 19. Behind the second pressure sensor 19 , the flow sensor 18 and the temperature sensor 21 , there is a first throttle valve 20. The reference measuring circuit A is connected in both directions via the first Section 2 of the tandem hydraulic pump to the test measuring circuit B via the second Section 2 of the tandem hydraulic pump. The measuring circuit used new oil. The connection of measuring circuit B is similar as measuring circuit A (Figure 3). By circuit B it is possible to simultaneously measure more different engine filter at once (max. 4 pieces) with two different types of engines oil. With laboratory device is also possible to simulate and compare different operational condition, e.g., a higher level of oil contamination or different level of filter clogging (Figure 3).

All sensors, first temperature sensor 12, second temperature sensor 21, third temperature sensor 28, fourth temperature sensor 37, first flow sensor 11, second flow sensor 18 , third flow sensor 27, fourth flow sensor 34, first pressure sensor 10, second sensor 19 of the pressure, the third pressure sensor 26, the fourth pressure sensor 35, and the frequency converter 5 are connected in two directions to computer 38 in the recording and evaluation circuit $C$ for the transmission and processing of the recorded data. Subsequently, the obtained data are processed by computer 38 in table and graphic format. If the measurement methodology is followed, the repeatability of the measurement in laboratory conditions is guaranteed, and thus the possibility of monitoring the influence of different degrees of contamination of oil fillings on the flow properties of filter materials and their ability to separate impurities is ensured. The device for simultaneous testing of flow properties of filter materials allows measuring the flow properties of original and tested filter materials in each circuit while maintaining the same input conditions, and monitoring the filtration efficiency using mineral, synthetic oil fillings, but also oil fillings with different degrees of contamination and pollution. During the measurements, it is possible to simulate the conditions that are achieved in the lubrication circuit of the internal combustion engine by means of the first heaters $(1,22)$ and throttle valves $(20,36)$. The device allows monitoring of operating conditions recorded by temperature sensors $(12,21,28$ and 37), flow sensors $(11,18,27$ and 34) and pressure sensors (10, 19, 26 and 35) depending on the selected rotation speed, which are set by means of frequency converter 5 and a load exerted by the first throttle valve 20 and the second throttle valve 36 . It is also possible to monitor the effect of contaminated oil fillings on filter materials and their ability to separate impurities.

\subsection{Calculation and Design of Laboratory Test Equipment Drive}

Operating conditions were considered when calculating and designing the drive of the hydraulic equipment, selecting a suitable electric motor, and using a tandem hydraulic pump. When designing the electric motor, we considered the suitability of using the given application (asynchronous motor). By using a frequency with an asynchronous motor, we have achieved rotation speed controllability in the required range, without the need to use 
a gearbox. A tandem hydraulic pump was used in the test equipment, the parameters of which are given in Table 2. One of the criteria for the use of that hydraulic pump was the operating temperature of the engine oil used and thus the use of suitable types of seals.

Table 2. Parameters of the Marzocchi ALPP2-D-13 hydraulic pump [12].

\begin{tabular}{cccccc}
\hline $\begin{array}{c}\text { Geometric Volume of } \\
\text { the Hydraulic Pump, } \\
\mathbf{c m}^{\mathbf{3}}\end{array}$ & $\begin{array}{c}\text { Volumetric Flow } \\
\text { Rate at } \mathbf{1 5 0 0} \mathbf{~ r p m ,} \\
\mathbf{d m}^{\mathbf{3}} / \mathbf{m i n}\end{array}$ & $\begin{array}{c}\text { Continuous } \\
\text { Operating } \\
\text { Pressure, } \mathbf{M P a}\end{array}$ & $\begin{array}{c}\text { Intermittent } \\
\text { Operating } \\
\text { Pressure, } \mathbf{M P a}\end{array}$ & $\begin{array}{c}\text { Peak } \\
\text { Pressure, } \\
\mathbf{M P a}\end{array}$ & $\begin{array}{c}\text { Maximum } \\
\text { Rotation Speed, } \\
\mathbf{r p m}\end{array}$ \\
\hline 9.6 & 13.7 & 25 & 27 & 29 & 3000 \\
\hline
\end{tabular}

\subsection{Calculation of the Nominal Diameter of the Hydraulic Line}

The design of the nominal diameter of the tube have to be based on the interdependence between the flow from the $Q_{H G}$ hydraulic pump, the flow velocity of the liquid $v$ and the cross section of the tube $S$. This dependence is given by the continuity relation:

$$
\mathrm{Q}_{\mathrm{HG}}=\mathrm{S} . \mathrm{v}
$$

where:

$\mathrm{Q}_{\mathrm{HG}}$-maximum flow rate of the hydraulic pump, $\mathrm{m}^{3} / \mathrm{s}$

$\mathrm{S}$ - tube cross section $\left(S=\frac{\pi D^{2}}{4}\right), \mathrm{m}^{2}$,

$\mathrm{v}$-fluid flow velocity, $\mathrm{m} / \mathrm{s}$

In this case, two quantities are unknown, namely the flow velocity of the liquid and the nominal diameter of the tube, which we want to calculate. Based on that a gear hydraulic pump will be used in the design of the hydrostatic dynamometer, the theoretical value of the flow rate will be determined by the relation for the circumferential velocity:

$$
\mathrm{v}=\omega \cdot \mathrm{r}
$$

where:

$\omega$-angular velocity $(\omega=2 \pi n), 1 / \mathrm{s}$

After adjusting the relation (5) and substituting it into the relation (4), we get a formula for calculating the inner diameter of the tube:

$$
\mathrm{d}=\sqrt[3]{\frac{4 \cdot \mathrm{Q}_{\mathrm{HG}}}{\pi^{2} \cdot \mathrm{n}_{\mathrm{HG}}}}
$$

where:

$\mathrm{n}_{\mathrm{HG}}$ - hydraulic pump rotation speed, $\mathrm{rpm}$

$\mathrm{d}$-diameter, $\mathrm{m}$

After substituting the data in the corresponding units into relation (6), the value of the internal clearance of the tube is calculated $d=19.6 \mathrm{~mm}$. According to the EN 10305-1 standard, the next highest value of the internal clearance of the hydraulic tube is selected, $\mathrm{d}=20 \mathrm{~mm}$ with a wall thickness $\mathrm{s}=2 \mathrm{~mm}$. From the parameters designed in this way, it is possible to recalculate the flow velocity of the liquid, resp. flow velocity range at varying hydraulic pump speeds (from $600 \mathrm{rpm}$ to $3000 \mathrm{rpm}$ ). At the maximum rotation speed of the hydraulic pump $\mathrm{n}_{\mathrm{HG}}=3000 \mathrm{rpm}$, the theoretical velocity of the liquid flow is approximately $\mathrm{v}=3.77 \mathrm{~m} / \mathrm{s}$ and the maximum theoretical flow from the hydraulic pump $\mathrm{Q}_{\mathrm{HG}}=28 \mathrm{dm}^{3} / \mathrm{min}$.

\subsection{Circulation Number Calculation}

For the calculation of the tank volume, the decisive volume of the oil filling was determined by the construction of the IVECO TECTOR 7 combustion engine. The amount 
of working fluid used in both circuits is given by the volume of the oil charge in said engine. The circulation number is calculated as the ratio of the flow of the hydraulic pump to the volume of the oil filling. The results of the calculation of the circulation number is that the oil filling is pumped for one hour through the test laboratory equipment 42.41 times per hour, measured at the rotation speed of the electric motor $1728 \mathrm{rpm}$ and the flow of the hydraulic pump $\mathrm{Q}_{\mathrm{HG}}$ nom $=16.26 \mathrm{dm}^{3} / \mathrm{min}$.

On the laboratory test device, Figure 4, verification measurements of the device were performed under the specified conditions:

1. test of pressure and flow characteristics of selected types of oil filters with uncontaminated engine oil at $30^{\circ} \mathrm{C}$ and $60^{\circ} \mathrm{C}$;

2. test of pressure and flow characteristics of selected types of oil filters with contaminated engine oil at $30^{\circ} \mathrm{C}$ and $60{ }^{\circ} \mathrm{C}$, collected from the IVECO CROSSWAY bus after $80,744 \mathrm{~km}$;

3. comparison and evaluation of measured values of pressure and flow characteristics of oil filter MANN W950/26;

4. comparison and evaluation of measured values of pressure and flow characteristics of oil filter $\mathrm{CNH}$ Industrial 2992242.

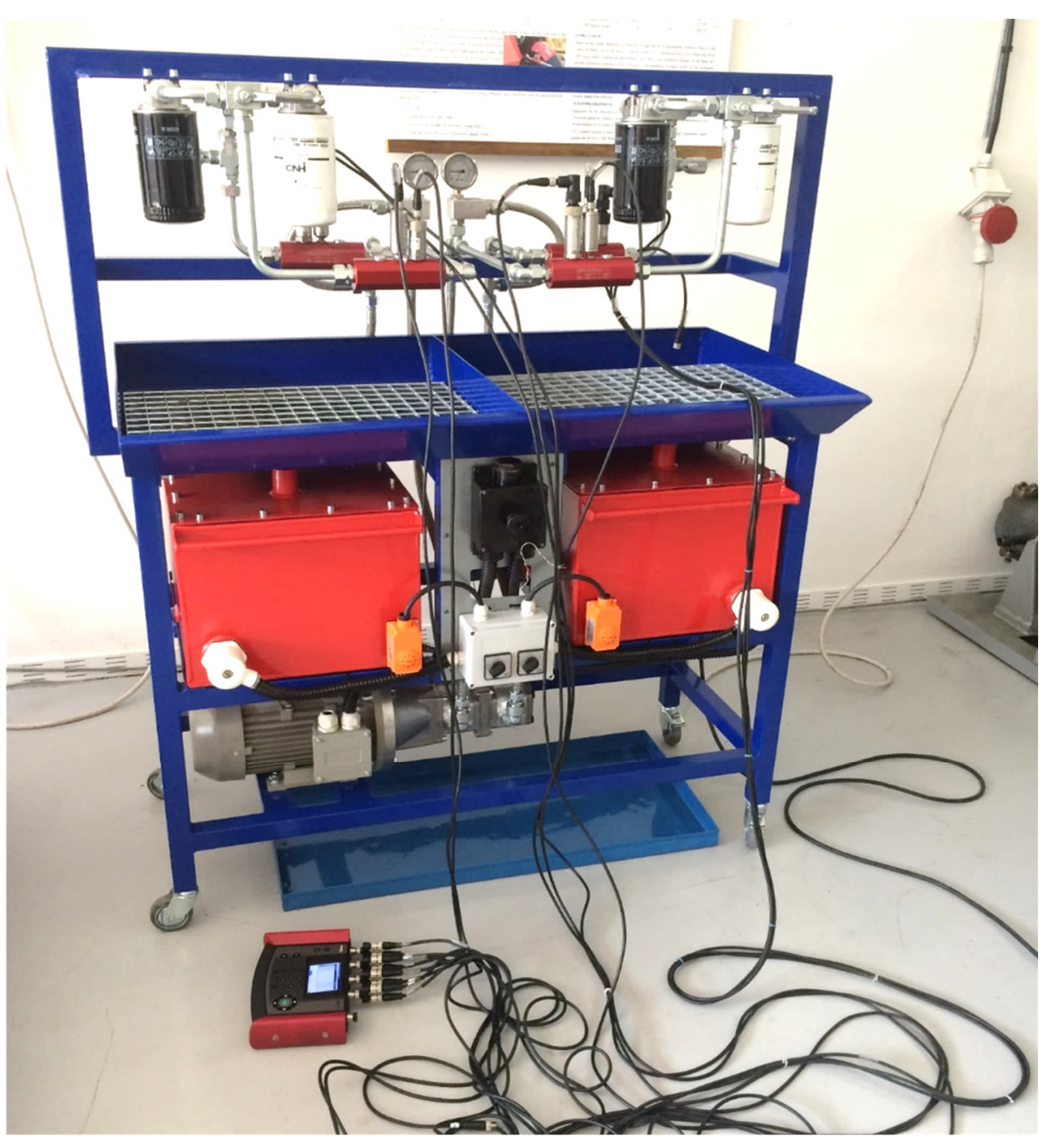

Figure 4. Laboratory test equipment for automotive oil filters to evaluate the technical life of engine oil.

Verification measurements under laboratory conditions were performed under the following conditions: 
- the measurement setting of the laboratory equipment must not change during the test, the position of the three-way valve in front of and behind the oil filters must not change;

- the operating temperature of the engine oil in both the test and reference circuits must be the same;

- the rotation speed of the hydraulic pump must correspond to the nominal rotation speed of the internal combustion engine IVECO TECTOR 7;

- when simulating the operating load, the rotation speed change of the hydraulic pump is realized by means of a frequency converter, according to the motor rotation sensed in the operating conditions;

- the rotation speed value after its setting must not change $\Delta \mathrm{n}= \pm 1 \%$ or $10 \mathrm{rpm}$, considering the higher value;

- for pressure and flow measurement, a minimum measurement time of $60 \mathrm{~s}$ is set, with recording of values in the interval $0.02 \mathrm{~s}$;

- unless otherwise specified by the manufacturer, the oil temperature must be in the range of $80-100^{\circ} \mathrm{C}$. Because the only verification measurement necessary was to check the right functionality of sensors and hydraulic circuit, we can set a lower temperature $\left(30^{\circ} \mathrm{C}\right.$ and $\left.60^{\circ} \mathrm{C}\right)$.

Verification of the functionality of the proposed laboratory test equipment was performed by verification measurements, using a new, uncontaminated engine oil and oil filter in the reference hydraulic circuit according to the specification specified by the manufacturer. Contaminated engine oil from operation using a MANN W950/26 oil filter and using a CNH Industrial 2992242 oil filter was used in the test circuit.

\section{Discussion}

Petranský [13] dealt with the issue of designing test hydraulic equipment in their work at the Department of Transport and Handling, Faculty of Engineering in Nitra, which created a set of measuring laboratory equipment for testing hydrostatic elements and hydraulic fluids. For testing filters that are used in conjunction with an internal combustion engine lubrication system, standardized tests specified by either the filter manufacturer or the final filter purchaser are used. When designing laboratory test equipment, the effort is to be as close as possible to the working conditions in normal operation. Laboratory tests are used in practice, which are focused on changes in hydraulic-mechanical characteristics (pressure and flow rate changes in the hydraulic circuit), filtration efficiency, which is determined by the coefficient $\beta$ (expresses the filterability as the ratio of the number of particles greater than the limit before the filter to the number of particles greater than the limit behind the filter according to the standard ISO 4572), chemical and temperature compatibility and permeability of the valves of the filter device. According to Kučera [14], if tribotechnical diagnostics is applied correctly and thoroughly, there can be significant savings in increasing the technical life of machinery and equipment, reducing energy consumption and reducing downtime. The basic tribotechnical diagnostics of oils is spectroscopy (spectrometry). Analysis of oils by spectroscopy was discussed by Tkáč [9], which evaluated the state of oils on the basis of the different absorption (absorption) of chemicals and their ability to emit (emit) light at different wavelengths.

The next research [15] dealt with the contamination of engine lubricating oils and their influence on tribological parameters that negatively affects engine performance and increases fuel consumption. He points out the fact that engine oil is most often contaminated with $\mathrm{Fe}, \mathrm{Cu}, \mathrm{Al}, \mathrm{Pb}$, and $\mathrm{SiO}_{2}$ particles. The presence of solid contaminants in motor oils leads to an increase in the coefficient of friction, wear, and friction losses, which increases the surface roughness. In the results, he showed that grain size and concentration significantly affected tribological parameters. In order to minimize the impact of solid contaminants, it is necessary to improve the filtration accuracy of lubricating oils. Gulzar and Masjuki [16] in their work focused on the modification of an oil filter for internal combustion engines powered by biodiesel, where the use of new filtration technology was 
adopted to neutralize acidic contaminants. Similarly, the author Puškár [17] in his study dealt with the analysis of biodiesel and its mixture for regulated and unregulated gaseous emissions of a diesel engine, this engine being the propulsion unit of a vehicle that can be used in standard road traffic. It is therefore possible to assume that this power unit would be used in a bus. By filtration chemical modification, the interval of lubricant outflow through the basic filter was improved, while it showed a significant and positive effect by slowing down the rate of lubricant degradation.

In his work, Junda Zhu [18] focused on monitoring the condition of lubricating oils and detecting degradation. The main purpose of monitoring the condition of the lubricating oil and detecting degradation is to determine whether the oils have deteriorated to such an extent that they no longer fulfill their functions. In particular, the evaluation of the lubricant efficiency and the remaining assumption of the life of the decomposed lubricating oil with the viscosity data, with the filterability of the lubricating oil contamination particles, are given. To demonstrate the effectiveness of the developed technique, a simulation study based on laboratory-validated models was provided. Laboratory models enable online monitoring of lubricating oils and the prediction of changes in oil properties using viscosity and dielectric constant sensors together with oil contaminant filtration technology.

The laboratory equipment allows testing the suitability of filters with different filtration capacity in simultaneous testing in two separate hydraulic circuits with different contaminated engine oil, without the risk of damage to the internal combustion engine. Determination of the extent of engine oil contamination before use in the test circuit will be made by evaluating the physical-chemical properties of the oil used and the degree of its contamination. The results of the evaluation of the filtration capacity of oil filters can be used in the design of new filter materials. Moreover, with a suitably determined methodology for changing oil filters and engine oil change intervals, it is possible to extend replacement intervals.

\section{Conclusions}

Some types of test are very difficult to perform directly under operating conditions due to possible damage to the internal combustion engine. This is because during the tests the course is affected by various adverse effects, such as the diversity of technical and operational conditions, the disproportionate load and the human factor. The testing of engine oil filters and their abilities should be solved in laboratory conditions on a specialized laboratory test device with the simulation of operating conditions. The aim of the presented article was the design of a laboratory device for the evaluation of engine oil filtration from the point of view of a possible extension of service intervals.

One of the conditions in the design of the test device was the application of the most modern methods of control and simulation, which are closest to the real operating conditions. The proposed laboratory test device allows the simultaneous testing of the filtration ability between different types of filters with different contamination levels of engine oil, with the exact repeatability of the tests.

The results of the verification measurement indicate the real use of the device to evaluate the filtration of engine oil under laboratory conditions, in the simulation of the operating load. The accuracy and wide possibilities of the laboratory device were proved by the performed verification measurements.

The construction of the laboratory test equipment together with the verification measurement of individual hydraulic circuits was carried out on the basis of practical questions on the possibility of replacing internal combustion engine oil filters with the possibility of extending service intervals to reduce operating costs and eliminate environmental impacts.

Author Contributions: Conceptualization and writing (original draft preparation), H.L'. and J.J.; methodology, T.J.; formal analysis, M.J. and S.M.; writing (review and editing), Z.M.; visualization, J.R. All authors have read and agreed to the published version of the manuscript.

Funding: This research received no external funding. 
Institutional Review Board Statement: Not applicable.

Informed Consent Statement: Not applicable.

Data Availability Statement: Not applicable.

Acknowledgments: This work was supported by project VEGA 1/0155/18 “Applied research of the use of ecological energy carriers in agricultural, forestry and transport technology." This work was supported by project KEGA 028SPU-4/2019 "Practical utilization of design and testing knowledge of transmission systems of hydraulic mechanisms of mobile agricultural and forestry machinery." This work was supported by project APVV SK-PL-18-0041 "The Development of Scientific Cooperation in the Study of the Effects of Biofuels in Road Transport, Including Environmental Impact." This publication was supported by the Operational Program Integrated Infrastructure within the project: Demand-driven research for the sustainable and innovative food, Drive4SIFood 313011V336, cofinanced by the European Regional Development Fund.

Conflicts of Interest: The authors declare no conflict of interest.

\section{References}

1. Stabilita Mazacích Olejov. Available online: http://www.tribotechnika.sk/tribotechnika-42012/stabilita-mazacich-olejov.html (accessed on 1 April 2012).

2. Pet'ková, V. Tribotechnika v Teórii a Praxi, 1st ed.; Vienala: Košice, Slovakia, 2012; ISBN 978-80-81260-57-5.

3. Kučera, M.; Aleš, Z.; Pexa, M. Detection and characterization of wear particles of universal tractor oil using of particles size analyzer. Agron. Res. 2016, 14, 1351-1360.

4. Turza, J.; Kopiláková, B. Kombinovaný stend pre meranie hydraulických prvkov. Hydraulika a pneumatika. Časopis Pre Hydraul. Pneum. A Autom. Tech. 2011, 1-2, 60-64.

5. Tóth, F.; Fürstenzeller, A.; Rusnák, J.; Bošanský, M.; Kadnár, M. The possibilities of using ecological liquids in tribological gliding systems with a selected surface created by the radial welding technology. Acta Technol. Agric. 2019, 22, 134-139. [CrossRef]

6. Semjonovs, J. Increasing of engine oil change interval by using additional oil filter in diesel engines. In Proceeding of 13th International Scientific Conference Engineering for Rural Development, Jelgava, Latvia, 29-30 May 2014; pp. 247-252.

7. Ziegler, J.; Helebrant, F.; Marasová, D. Technická Diagnostika a Spolehlivost, Díl I. Tribodiagnostika, 1st ed.; Technická Univerzita Ostrava: Ostrava, Czech Republic, 2004; ISBN 80-7078-883-6.

8. Tribotechnická Diagnostika v Automobilovom Priemysle. Available online: http://www.tribotechnika.sk/tribotechnika-1-2009 /tribotechnicka-diagnostika-v-automobilovom-priemysle.html (accessed on 1 January 2019).

9. Tkáč, Z.; Drabant, Š.; Majdan, R.; Cvíčela, P. Testing stands for laboratory tests of hydrostatic pump of agricultural machinery. Resarch Agric. Eng. 2008, 54, 127-141. [CrossRef]

10. Kučík, P. Prevádzka Hydraulických Zariadení, 1st ed.; Fluidconsult, s.r.o.: Žilina, Slovakia, 2010; ISBN 978-80-97052-40-9.

11. Products Hydac. Available online: https://www.hydac.com (accessed on 8 November 2020).

12. Cross Gear Pump ALP2D Series. Available online: https://www.crosshydraulics.com.au/files/products/gearPumps/ALP2 _Series.pdf (accessed on 10 October 2020).

13. Petranský, I.; Drabant, Š.; Tkáč, Z.; Žikla, A.; Bolla, M.; Kleinedler, P. Skúšobné Stavy pre Životnostné Skúšky Hydrostatických Prevodnikov, 1st ed.; Slovenská Pol'nohospodárska Univerzita v Nitre: Nitra, Slovakia, 2004; ISBN 978-80-80693-43-5.

14. Kučera, M.; Aleš, Z.; Ivandić, Z.; Hujo, L'. Possibility of hydraulic fluids with a low environmental impact application in agriculture and transport machinery. J. Cent. Eur. Agric. 2013, 14, 1592-1601. [CrossRef]

15. Effect of Lubricant Contaminants on Tribological Characteristics during Boundary Lubrication Reciprocating Sliding. Available online: https:/ / arxiv.org/ftp/arxiv/papers/1710/1710.04448.pdf (accessed on 8 November 2020).

16. Gulzar, M.; Masjuki, H. Oil filter modification for biodiesel-fueled engine: A pathway to lubricant sustainability and exhaust emissions reduction. Energy Convers. Manag. 2015, 91, 168-175. [CrossRef]

17. Puškár, M.; Jahnátek, A.; Kuric, I.; Kádárová, J.; Kopas, M.; Šoltésová, M. Complex analysis of influence of biodiesel and its mixture on regulated and unregulated emissions of motor vehicles with the aim to protect air quality and environment. Air Qual. Atmos. Health 2019, 12, 855-864. [CrossRef]

18. Junda, Z.; Jae, Y.; David, H.; Aaron, Q.; Bechhoefer, E. Lubrication Oil Condition Monitoring and Remaining Useful Life Prediction with Particle Filtering. Int. J. Progn. Health Manag. 2017, 4, 1-15. 